\title{
An Analysis on the Symbolic Meaning of 'Buildings' in Samak Ayyar Story
}

\author{
Zaynab Choghadi $^{1} \&$ Mahdi Noorian ${ }^{1}$ \\ ${ }^{1}$ Literature department, University of Isfahan, Isfahan, Iran \\ Correspondence: Zaynab Choghadi, Literature department, University of Isfahan, Isfahan, Iran. Tel: \\ 98-913-329-1699. E-mail: zeynabchoghadi@yahoo.com
}

Received: April 27, 2013 Accepted: March 20, 2013 Online Published: June 26, 2013

doi:10.5539/ach.v5n2p174 URL: http://dx.doi.org/10.5539/ach.v5n2p174

\begin{abstract}
Old stories, rather than being a means to shorten the long winter nights or make children's eyelids heavy, were the hidden treasures of peoples' social and psychological history. They contained, more than anything else, archetypal motifs which were expressed through various symbols. One such old stories was SamakAyyar which appeared in the north-eastern region of the Iranian plateau. The initial narrators of SamakAyyar were most probably the Aryan branch of the Indo-Aryan settlers. The fact that Aryans were neighbouring the Hindu cultures on the one hand, and the common ancestors as well as ideas of the two nations on the other, resulted in the footprints of Buddhist beliefs and Hindu rituals in this story. The influence of these beliefs can clearly be observed in the description of the buildings which appear in the story.Suchbuildings become sacred due to their association with the story plot, i.e. the journey from childhood to maturity. Whether a prison, palace or a castle, the structural image of these buildings, generally and frequently, resemble the Hindu temple. It seems as though such similarity follows the same sense as that in the construction of sacred buildings, especially Hindu temples. The inner journey, moving in circular directions, and the relationship between heaven and earth are instances of this holy meaning. Such concepts are discussed in the analysis of the symbolic meaning of the buildings in the story.
\end{abstract}

Keywords: Samak Ayyar, symbolic building, Hindu temple, journey inside

\section{Introduction}

The story of SamakAyyar is an ancient Persian tradition. Corbin(2005), maintains that the evidence extracted from the text, such as non-Islamic names, structure of a feudal society, lack of mosques, mass drinking and casket burials, dates the story back to a pre-Islamic era, circa the Parthian ${ }^{1}$ period In addition, the wide usage of Turkish and Mongolian names merely associated with slaves and militias, supports the hypothesis of the story being originated in the north-eastern parts of the Iranian plateau, the ancient Parthians' territory - where the influence of Turkish nomads as serfs and soldiers was an early custom and later in the $11^{\text {th }}$ and $12^{\text {th }}$ Century AD great Turkish kingdoms took place. Moreover, the hero of the story journeys eastwards to China in the pursuit of his ambition. The emphasis on the Eastern origins of the narrative is owed to the effects of the ancient heritage of a doctrine belonging to the Aryans branch of the Indo-Aryan family on the mythological motif of the story, and consequently the formation and expression of symbols and, in particular, the imagery of conceptually symbolic buildings. The Image of the story's main buildings follows a Mandala ${ }^{2}$ rationale which has most likely taken its foundation from the Aryans' knowledge of ancient Hindu beliefs. Buildings that through their similar and popular design, four-door squares in the middle of an either visible or hypothetical circle, reminisce a Hindu temple. Hogget(1976),concludes that the temple's mandala design compounds circles and squares, which in modern Buddhism are an indication of the universe and its spiritual forces. The passage from childhood into maturity, being the plot of the story, confirms the theory of a sacred principal in the monuments; as in ancient religions, this great transformation has always been in connection with the concept of sacrifice in an altar or a temple. Similarly, in this story, in a course to the perfection of his personality, a prince undergoes great austerity to sacrifice his old "self" in order to be worthy of the kingdom of a world that in a deeper sense is within him. During his transmutation, he comes upon four stages of plight and imprisonment, which happen in buildings with similar and meaningful structures, repeated throughout the story. Analysis of the buildings' Mandala pattern and the hypothesis of their similarity to Hindu temples, are the subject of this article. 


\section{Description of the Buildings in "SamakAyyar"}

SamakAyyar tells the adventures of the Prince of Aleppo who, as a consequence of a magical meeting with the Chinese princess, defies his father and takes on a challenging journey, passing through numerous tests. During these stages, he passes by buildings, castles and prisons which their description oddly follows a quadratic logic. At first glance, the detailed description of buildings somehow related to the Chinese Princess, 'Mah Parry' (Angle of Beauty), or the hero of the story, 'Khorshid Shah' (King of the Sun), may seem as a storytelling trick or a way to prolong the narrative; but once these depictions are put together, a unique and meaningful portrayal, inclusive of motifs similar to other ancient traditions, is achieved. Quad numeral logic, Mandala spaces with opposing door, and impenetrable oval fortresses, confirm the belief that these buildings have a symbolic significance. A comprehensive description of Mah Parry's tent, as an important fact, begins the tale. A mystified tent where crossing its threshold is a sign of the hero's first step on his way to transformation. Among the nomadic nations of the northeast, a circular tent meant the sky, and a place for sacrifice. Sacrificial tents of the nomadic nations show the closest form of the skies to land. The tent's pillar was raised aligned with the polar star. Some believe that the middle pillar of Buddhist temples has emerged through an inspiration by the same pattern (Zekrgoo, 2004).

The majority of holy sites, the Shiva temples, the Buddhist Stupa ${ }^{3}$, or the Muslim mosques, represent a symbolic concept of unity between heaven and earth. Mah Parry's tent also, having a moon on the top and twenty-four Golden spikes, has a celestial sense. The number 'Twenty-four' symbolizes the cosmic balance and compliance of time. This number displays the relationship between perpetual eras and cyclical needs. Twenty-four' is of the most common numbers in Eastern and Western fairy tales. In these stories, 'Twenty-four' represents the collected powers of mankind the totality of rudimental quiddities. In addition, this number signifies the increasing harmonization of heaven and earth, divine blessings and eternal life (Chevalier \& Gheerbrant, 2009). The circular pattern denotes the sky, and its connection to the ground by the twenty-four ropes, symbolizes the union of the two. This tent is the place for the symbolic inception of the transformation ritual. From here, the prince faces change and challenges which will in turn make him worthy of approaching the world of adults and becoming his father's heir to the throne. The magical tent appearing in the middle of an arid and fearful desert, undoubtedly, evokes a holy place, such as a desert dwellers, altar, round alters, which among the Parthian settlers gradually turned into square shaped temples and the circular concept remained in the spherical dome or the pool in the middle. It is fascinating that Princes' Prison, the first building described in the story, has a rectangular Mandala design, suggesting the theory of Shaman's tent being transformed into a square temple. The alteration of circular altars with rectangular altars and temples in the Parthians' rituals is the difference between nomadic and sedentary Indo-Aryan nations. Burckhardt (2011), points out that among the nomadic nations square buildings represents freezing and death. They look for their ideals in the dynamism and natural immensity of a circle, while the settlers looked for it in the static characteristic and orderly shape of a square. The buildings debated in the following, such as the modern shape of Stupa and Hindu temples, are a combination of circles and squares and, subsequently, there is a collaboration and symmetry of static concepts and death with rebirth in the story. These structures appear on three levels of underground, ground, and sky, which also evoke the cosmic axis of Stupa - an axis that connects the three. According to Varro, there are three kinds of temples: the Temple of Heaven, Temple of the Earth and Temple of the Underworld (Zekrgoo, 2004).

\subsection{Temple of the Underworld, Princes' Prison and the Fish House}

Mah Parry's nursemaid, through guile and cunning, kidnaps her suitors and takes them to an unknown location. Khorshid Shah finds the underground Prince's Prison, with four doorways on four opposing balconie.

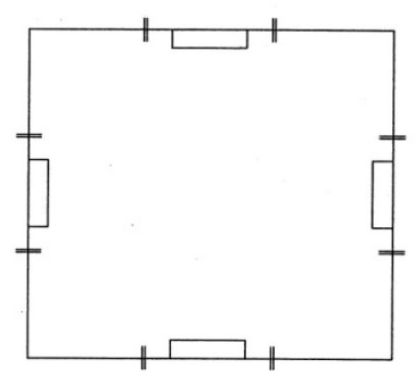

Figure 1. The princes' prison 
Such a room is a cross-shaped Mandala image on which the original design of Hindu temple is established. It is based on temples such as the Shiva-Shakti that the recent North Tibetan Mandala pattern has emerged(Zimmer, 1953: 144).

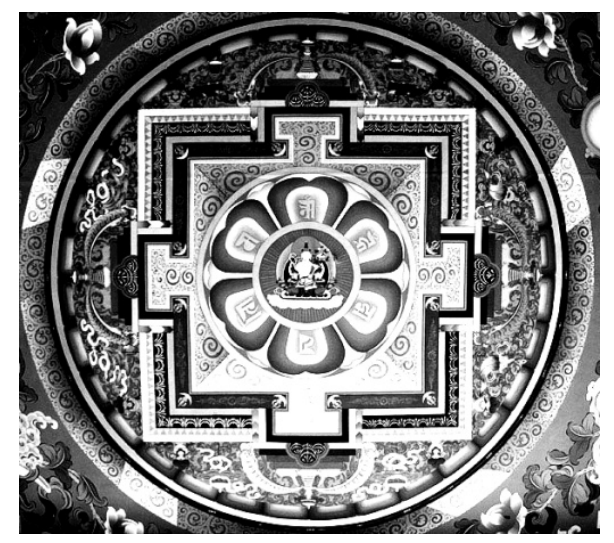

Figure 2. Mandala imprinted on the wall of the Boudhanath temple

Four-doorway structure is inscribed into an imaginary compass circle. The square or cube shape of a sacred building is the expression of certainty and irreversibility of an indispensable law. Hence, any type of sacred architecture, belonging to any tradition, is interpretable to the fundamental theme of transforming a circle into a square. In the development of the Hindu Temple, this theme has a particular clarity, and arises through all its rich metaphysical and spiritual content (ibid).

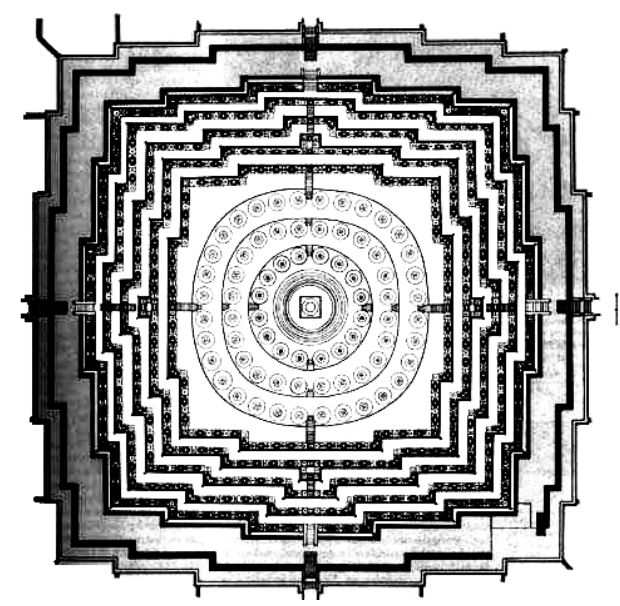

Figure 3. Architectural plan of a Hindu Temple

In fact, in the mythology of most cultures, this symbol represents the earth. At large, the number 'four' has semantic roots in mythology and, therefore, in sacred architecture. Described in the Qur'an are four gardens for the righteous and the noble, each with a distinct fruit. The Qur'anic concept of architecture has had an impact on gardens and palaces in Islamic countries and around the world (Clarke, 2003). The SamakAyyar story falls in cellars, castles, tunnels, basements and square buildings; a feature that places it among location-related myths. Loeffler-Delachaux (2006) claims that in most legends, caves, fissures, basements, cellars, and other completely dark spaces are symbols of a mother's womb. These symbolic elements are directly related to the transition from adolescence to adulthood, thorough which teens experience a daunting, gruesome and grave-like space, with the promise of rebirth and becoming a mature man able to reproduce. The concept of maturity, fertility, and the ceremonial rebirth in this tale, requires Mah Parry to be seen in every building or within its purpose. The girl with whose desire, the hero started his challenging voyage. As can be seen in the story of 'The Stone Avenue', Khorshid Shah and a group of his allies are trapped in a dead-end road and, in order to escape, they start a tunnel 
at the end of the alley. Their underpass reaches a staircase which leads to a rectangular basement with four opposing porches.

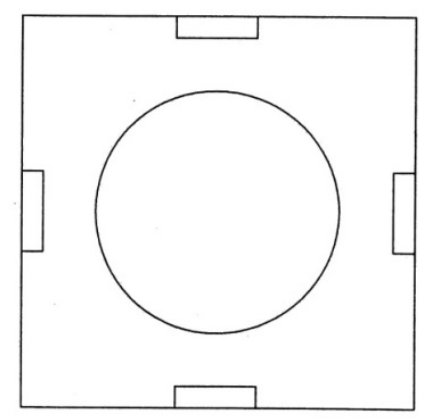

Figure 4. The fish house

The difference between this place and the Princes' Prison is that these porches are enclosed, but at its centre, there is a fish house with a canal way out, passable for one man at a time (Faramarz-Ibn-Khodadad, 2006). As previously mentioned, the construction of a pool or fish house in the middle of a square shaped structure reflects the circular nomadic altars. On the other side of the canal out of The Fish House is the garden where Mah Parry resides. Their entrapment in the underground space has the means of stagnation and death whereas the way out and meeting Mah Parry promises salvation and rebirth. The Prince's Forces, which are merely his mental powers and facilities, are symbolically placed in a space which shows the groundwork of, the plot of SamakAyyar story, the transformation process.

\subsection{Temple of Heaven, Shahak Castle, and Falaki Castle}

Mah Parry, the story's incentive of journey and promise of fertility, is captured in a castle as described, "Samak toured the castle. He laid eyes on a mountain created by the almighty God, isolated from others, round as a chicken ovum, raised to the skies and a narrow road failed to pass more than one rider ... Samak was seeing a castle that had secrets with the heavens and conversations with the people" (Faramarz-Ibn-Khodadad, 2006). The description the castle is not far from the early Buddhist Stupa. The oval shape of the fortress recalls 'Anda', the round body of the Stupa, which is compared to a chicken egg, since it is home to Nirvana's seed, the ashes of Buddha (Zekrgoo, 2004).

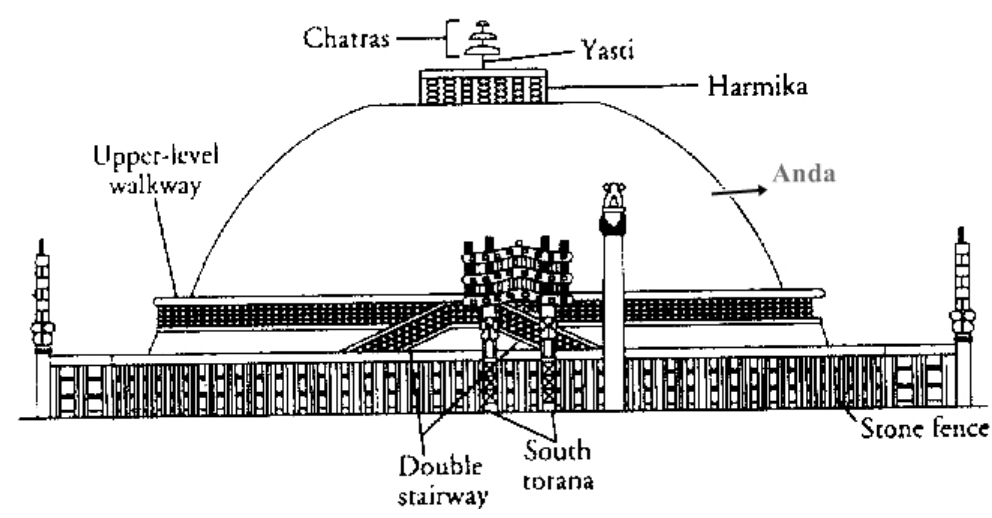

Figure 5. Buddhist Stupa-Anda

The essence of life and movement in the fictional world of SamakAyyar is Mah Parry - the potential and limited powers fertility and development that are in the Prince's individuality. Now this force of fertility and life is trapped in an oval castle on a mountain peak. Mah Parry also gets imprisoned in another castle called 'Celestial Castle'. A high impenetrable fortress, termed 'Celestial' due to its height and circularity. There only is a narrow path for a rider which leads to the foot of the wall (Faramarz-Ibn-Khodadad, 2004). The name means 'fortress of the sky' which associates its circular image with the sky. On the other hand, the castle has twelve towers in each 
of which, the guard spends each night (Faramarz-Ibn-Khodadad, 2004). The description of these twelve towers, in addition to the circular shape of the castle, insists on the building's cosmic concept. So far, for each of the two rectangular Mandala basements, there has been an elevated circular castle. The two underground squares are men's jails and the castles are Mah Parry's. It must be noted that Mah Parry's imprisonment in the Celestial Castle is not irrelevant to the myth of Father Sky and Mother Earth.Loeffler-Delachaux (1950), believes thataccording to the myth of Father Sky and Mother Earth, due to an incident, the couple have fallen separate, and therefore a virgin girl is confined in a high castle as an offering to Father Sky. The description of rectangular basements and circular castle in contradiction and interaction with one another shows an unbroken bond between the two; shapes that, in all forms of sacred buildings, are interpreted through their interaction, conflict, or confrontation. Their association, through its positive and negative aspects, constantly tells of a deep and unbroken relationship between the two abstract shapes and in various cultures explains the link between heaven and earth in a mutual and applicable manner. That is why the Chinese Kings' apparel consisted of a round collar and a rectangular shaped skirt which wrapped the king like the intermediary between heaven and earth (De Beaucorps, 1994). The continuity of squares and circles frequently signifies heaven and earth and the tie between the two. If circle symbolizes the sky, then square is for the earth and if circle stands for time, square is for location. "In Iranian architecture square is transformed into circle (dome) which means a limited shape with a beginning and an end becomes a limitless one with no start and no finish" (Nouraghaie, 1390). The Buddhist Mandala and the Hindu Shiva Temple are also squares with four opposing thresholds, within a circle that doesn't necessarily exist; but the rotary concept is always attached to this architecture. Mandala expresses the concept of union or interaction between heaven and earth. This interaction or encounter, which contains nexus content, appears in the symbolic form the SamakAyyar story structures. Two rectangular Mandala basements against two tall circular castles, with one being explicitly compared to an egg, indicate a mental image of the early universe. Captivity of the story's lady in a globular structure suggests, based on ancient notions, the concept of mobility and birth; whereas the incarceration of men in the square Mandala cellars carries the meaning of stagnation, death and rebirth. The common descriptive point in all of the story buildings, is their narrow entry ways which let only one man through. Challenging one-man passages reflect the ancient ritual of transformation; a ritual that in a variety of cultures has been celebrated in holy places, through harsh endurances and impassable crossings. In this story also, finding Mah Parry is only achieved through a beam of a path and facing overwhelming risks.

\subsection{Temple of the Earth, the Treasure House}

Khorshid Shah's chief ally, SamakAyyar, having infiltrated and searched the Celestial Castle, finds a secret room in which a priceless treasure is concealed. The room has Mandala architecture just alike the Princes' Prison and the Fish Room. The description of this Treasure House is no different from the earlier described rectangular buildings. The treasure found by Samak, is truly equivalent to the tale's ultimate sense and finding Mah Parry. Below the Treasure House is another room with the same Mandala plan. "He saw a chamber, having four opposing platforms, with a majestic vat on each. On the side a door was built into the ground, so he crushed it. A ladder appeared and they climbed it down. He saw a basement, having four opposing platforms full of gold" (Faramarz-Ibn-Khodadad, 2004).

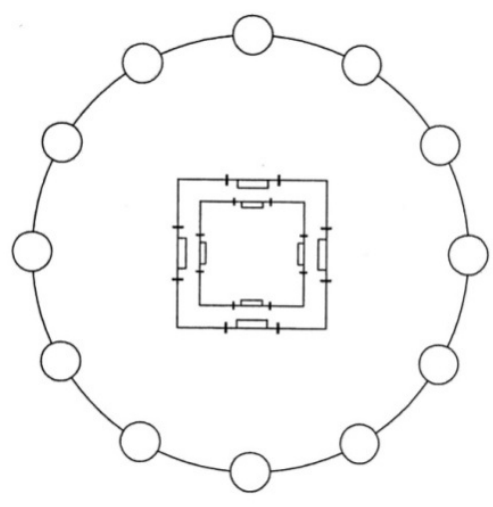

Figure 6 . The treasure house 
The Discovery of the treasures house and subsequently the basement room, is another form of finding the Princes' Prison. SamakAyyar is the symbol of a part of the hero which in his journey within has achieved a sense of realisation towards some of the darkest corners of his own self. In actuality, the hero, through his active and potential possibilities, searches for his hidden abilities and unknown talents and finds a treasure inside, deeper and more valuable than any treasure. The contemplation through labyrinths such as the Princes' Prison, Fish House and the Treasure Room, symbolically represents the inner journey. This finding and consciousness releases the potential and makes the star worthy of individual mentality and unison of different aspects of his personality. Labyrinths in sacred architecture represent deep self-awareness; moving from the dome to the Earth and to the Underworld recalls the inner journey. Just as the various levels of the Eastern temples are interpreted to different territories of body and soul, Brereton (1987), concludes that the Hindu temple represents the human body and so a trip to the temple, is a voyage into self. Coming into contact with God's image in the heart of the temple, symbolically repeats God's visit to the heart of one's existence. According to MirceaEliade's paradigm of a sacred space, the main vertical divisions of the universe intersect and reflect each other in the holy space. These partitions merely include the upper world, the earth, and the underworld.

As in the Celestial Castle, the three dominions of sky, earth and underworld are interconnected, the foundation to an alliance on the discrete shards of Khorshid Shah's mind-set is also provided. These three empires are particularly evident in his allies joining him, his marriage to Mah Parry, and his unity with his father. The unbreakable unison of heaven and earth provides grounds for a link between the feminine and masculine aspects of the narrative.

\section{Results}

SamakAyyar, like every other ancient legend, narrates, in a symbolic tone, the peoples' rituals, beliefs, concerns and aspirations. Hence, in the core of these fictional examples and narrative elements, a latent concept reveals the social, cultural and ethnic legacy of a nation. The story depicts landmark buildings through the same and frequent description and in a Mandala structure in the interaction of squares and circles. This is the reminiscent of Hindu temples. Since the ancient Persian and Indian nations were of the same origins and shared beliefs, mythology and fundamental rituals, it seems that the buildings' designs have been affected by the iconic structures of Hindu and Buddhist temples in Central Asia. This is most probably due to the emergence of the story in the north-eastern part of the Iranian plateau which was neighbouring the nomadic Central Asian nations. The theme of the story, which narrates the ancient rituals of the journey to maturity, also strengthens the thought of a sacred meaning associated with its landmark buildings. In SamakAyyar, the edifices represent the blessed association of heaven and earth in the form of circles and squares. The most comprehensive description of a structure appears at the last stage of the prince's tests; where in the Celestial Castle, the three realms of sky, earth and the underworld are connected together through the shape of a dome, rectangular treasure house with four podiums to each side, and the basement with a similar design. This building is similar to the modern Buddhist Stupa, where the various dimensions of the universe are shown in combination. Their unity in the last stage of the story is the introduction to an alliance in the hero's sporadic mentality. Having passed this castle, the Prince comes to unity with his father and marries the Chinese Princess - a marriage that ties the story's geographical east and west, for Khorshid Shah to rule a world of singularity. This symbolic unity represents the person's psychological individuality, having left behind the challenging journey into maturity.

\section{References}

Akbari, A. (2005). The difference between Statue and Stupa. Tandis (Vol. 5).

Beaucorps, M. (1994). Les SymbolesVivants. Tehran, Markaz.

Bereton, J. (1987). “sacredspace” Encyclopedia of Religion. New York, 3, 526-535.

Burckhardt, T. (2011). Principles and Methods. Tehran, Soroosh.

Chevalier, J., \& Gheerbrant, A. (2009). Dictionnaire des symbols: myths, reves, coutumes. Tehran, Jeihoon.

Clark, E. (2003). Al Hamra Gardens. Proceeding of the first Religious Art Congress. Tehran, Iran.

Corbin, H. (2005). Youthfulness and Chivalry in Iranian Islam. Tehran, Markaz.

De Beaucorps, M. (1994). Les symbols vivants. Tehran, Markaz.

FaramarzIbn, K. (2008). SamakAyyar. Edited by natelKhanlari. Tehran, Agah.

Hall, J. (2001). Illustrated Dictionary of Subjects and Symbols in Eastern and Western Art. Tehran.

Hogget, E. (1976). Mandala and Boudhanath. The Buddhist temple. Payam UNESCO. 
Loeffer-Delachaux, M. (1950). Les symbolism des legends. Paris, L Arche.

Nikjoo, M. (1975). Parths, unknown nation in Persian history. Literature Journal, 41.

Nooraghayee, A. (2011). Number, Symbol, Myth. Tehran, Afkar.

Zekrgoo, A. (2004). Buddhist architecture and its symbolic features. Khial.

Zimmer, H. (1953). In J. Campbell (Ed.), Myth and symbols in Indian art and civilization. New York, Pantheon Books Inc.

\section{Notes}

Note 1. Parthians: of the Aryan family who lived in the east of the Iranian plateau around the ninth century BC. Some have associated them as neighbours and concurrent with nomadic Central Asian nations and related to the Scythians; but their connection, in terms of religion and language, to the residents of the central parts of the Iranian plateau has been unquestionably proven (Nikjoo, 1975)

Note 2. Mandala: Sanskrit word meaning circle, circular, sphere, orbit, reel, etc. The symbol can be found in India, China, Indonesia, and Japan, but its source is in Tibet. Tibetan Mandala is a four-door square within a circle. The doors are in the middle of each side, and to each of the four main directions.

Note 3. Stupa: in the beginning, consisted of eight sacred hills with Buddha's ashes on its peak. It gradually, changed into Buddhist temples with a circular plan and four opposing doors to each of the main directions. The structure is made of a dome on a circular or rectangular pillar. Positioned atop the stupa dome is a platform, called Harmika, with a spire on it known as a Yasti. Furthermore, the dome is surrounded by a stone fence and four gates. The oval-shaped dome is called 'Anda' which sustains the essence of life. Harmika symbolizes the heavens and Yasti is the line that connects the universe and paradise (Akbari, 2001).

\section{Copyrights}

Copyright for this articleis retained by the author(s), with first publication rights granted to the journal.

This is an open-access article distributed under the terms and conditions of the CreativeCommons Attribution license (http://creativecommons.org/licenses/by/3.0/). 